\title{
The impact of population ageing on end- of-life care in Scotland: projections of place of death and recommendations for future service provision
}

Anne M. Finucane ${ }^{1,2^{*}+}$ (D), Anna E. Bone $e^{3 \dagger}$, Catherine J. Evans ${ }^{3}$, Barbara Gomes ${ }^{3,4}$, Richard Meade ${ }^{5}$, Irene J. Higginson ${ }^{3}$ and Scott A. Murray ${ }^{6}$

\begin{abstract}
Background: Global annual deaths are rising. It is essential to examine where future deaths may occur to facilitate decisions regarding future service provision and resource allocation.

Aims: To project where people will die from 2017 to 2040 in an ageing country with advanced integrated palliative care, and to prioritise recommendations based on these trends.

Methods: Population-based trend analysis of place of death for people that died in Scotland (2004-2016) and projections using simple linear modelling (2017-2040); Transparent Expert Consultation to prioritise recommendations in response to projections.

Results: Deaths are projected to increase by 15.9\% from 56,728 in 2016 (32.8\% aged 85+ years) to 65,757 deaths in 2040 (45\% aged 85+ years). Between 2004 and 2016, proportions of home and care home deaths increased (19.823.4\% and 14.5-18.8\%), while the proportion of hospital deaths declined (58.0-50.1\%). If current trends continue, the numbers of deaths at home and in care homes will increase, and two-thirds will die outside hospital by 2040. To sustain current trends, priorities include: 1) to increase and upskill a community health and social care workforce through education, training and valuing of care work; 2) to build community care capacity through informal carer support and community engagement; 3) to stimulate a realistic public debate on death, dying and sustainable funding.
\end{abstract}

Conclusion: To sustain current trends, health and social care provision in the community needs to grow to support nearly 60\% more people at the end-of-life by 2040; otherwise hospital deaths will increase.

Keywords: Forecasts, Projections, Frailty, Palliative care, Place of death, Care homes, Nursing homes

\section{Background}

Worldwide deaths are projected to rise from 55 million in 2016 to 75 million by 2040 [1]. Non-communicable diseases accounted for $72 \%$ of global deaths in 2016, and may account for $81 \%$ of deaths by 2040 [1]. Globally the proportion of people aged 80 or over increased by $77 \%$ between 2000 and 2015 [2]. These demographic shifts

\footnotetext{
*Correspondence: Anne.finucane@mariecurie.org.uk

Anne M. Finucane and Anna E. Bone are Joint first authors

${ }^{1}$ Marie Curie Hospice Edinburgh, 45 Frogston Road West, Edinburgh, Scotland, UK

${ }^{2}$ Usher Institute, University of Edinburgh, Edinburgh, Scotland, UK

Full list of author information is available at the end of the article
}

require care systems to adapt to address the concerns of the growing older population.

In Scotland, with a population of 5.4 million, deaths increased moderately over the last decade from 55,986 deaths in 2007 to 57,883 in 2017 [3]. Causes of death are changing, with more people dying from dementia and Alzheimer's (4.6\% in 2006 to $11.3 \%$ in 2017), and steady decreases in deaths from cerebrovascular or ischaemic heart disease (from $27.2 \%$ in 2006 to $18.4 \%$ in 2017) [3]. Deaths from cancer have remained stable $(27.4 \%$ in 2006 to $28 \%$ in 2017). The average age at death in 2017 was 77 years, an increase from 75 years in 2006 [3]. People

(c) The Author(s). 2019 Open Access This article is distributed under the terms of the Creative Commons Attribution 4.0 International License (http://creativecommons.org/licenses/by/4.0/), which permits unrestricted use, distribution, and 
aged 85 and over accounted for one-third of all deaths in 2017; this is projected to rise to $45 \%$ by 2040 [3, 4].

An understanding of where people may die in the future is essential to facilitate planning and optimise resource allocation. It can act as a baseline measure to evaluate progress in shifting resources across care settings. Given that many people express a preference to die at home if circumstances allow [5], death in a community setting may act as a proxy indicator of whether preference was met.

Place of death trends differ considerably by country and may relate to the degree of palliative care integration within the wider health system. Trends in Scotland emerge within a context where specialist palliative care services are at a stage of advanced integration into mainstream service provision [6]. Comprehensive provision of all types of palliative care is offered by multiple providers and there is a broad awareness of palliative care on the part of health professionals, local communities, policymakers and society. In Scotland, and across the UK, the integration of health and social care is progressing, aiming to facilitate greater co-ordination between health and social services in coming decades.

Countrywide studies have projected trends in place of death for England and Wales [7], Portugal [8], Germany [9] and Belgium [10]. Data from England and Wales project a $25 \%$ increase in the number of annual deaths by 2040; if current trends continue, more people will die at home and in care homes, with care home becoming the most common place of death by 2040 [7]. In Germany, home deaths and nursing home deaths are expected to increase [9], and in Belgium deaths in care homes are projected to rise [10].

However, in Portugal, a country with a scarcity of palliative care services and little integration, projections show that if current trends continue, hospital deaths will account for nearly three-quarters of all deaths by 2030 [8]. In countries with ageing populations where palliative care is localised and less well integrated into the broader system, the development of more integrated models of palliative care are required as a first step before significant shifts from death in hospital to community settings can be realised [8].

We aim to i) project where people in Scotland will die up to 2040 and ii) identify expert recommendations for future care provision based on the projected data. Our findings will inform decision-making regarding resource allocation, service commissioning and service innovation for end-of-life care in Scotland.

\section{Methods}

\section{Study design}

Population-based trend analysis and projections using simple linear modelling to project place of death in
Scotland for each year from 2017 to 2040, building on the methods of Gomes and Higginson [11] and Bone et al. [7], followed by a Transparent Expert Consultation [12] to develop recommendations for service delivery to meet projected future needs.

\section{Data sources}

We obtained routinely collected death registration data 2004-2016 by age and gender from the National Records of Scotland (NRS) [3]. We categorised place of death according to NRS reporting standards, with the exception of hospice deaths, which were separated from the 'care home' category by the NRS at our request (Additional file 1). Place of death categories included 'own home' (non-institution and person's usual residence), 'care home' (includes nursing homes and residential homes without nurses), 'NHS hospital', 'hospice' and 'other' (e.g. road, shop, prison, school).

We accessed official projected future deaths for the population of Scotland (2017 to 2040) by age and gender from the Office of National Statistics (ONS) [4]. We used the ONS 2016-based national principal population projections [4]. Projected deaths were grouped into seven age categories (0-4 years, 5-14, 15-44, 45-64, $65-74,75-84,85$ and over) and by gender.

\section{Data analysis}

We first described the number and proportion of people dying in each age and gender group observed between 2004 and 2016, and the projected deaths by age and gender up to 2040. We calculated the proportion of people in each age and gender group who died in each care setting (2004-2016). We applied estimated age and gender-specific proportions of deaths by place of death to the projected deaths in each age and gender stratum for each year up to 2040 to estimate future place of death, based on an established methodology [7, 11, 13]. We modelled four scenarios. Scenarios 1-3 were derived from the latest England and Wales projections and allow comparability [7]. We added an additional scenario (Scenario 4) to allow us to project trends if primary and social care resource is limited to current levels and community deaths do not increase beyond 2016 levels.

- Scenario 1 assumed no change in the age and gender specific proportions of deaths observed in 2016 in each place of death.

- Scenario 2 assumed that the mean yearly change in age and gender specific proportions of deaths in each place of death that occurred between 2004 and 2016 continues.

- Scenario 3 assumed that the mean yearly change in age and gender specific proportions of deaths in each place of death that occurred between 2004 and 
2016 continues, but that care home deaths do not increase above the number observed in 2016, with any additional deaths instead occurring in hospital.

- Scenario 4 assumed scenario 3 above, but that home deaths as well as care home deaths do not increase above their absolute numbers in 2016.

\section{Expert consultation \\ Participants}

The study team identified experts in palliative care, primary care and social care with representation from commissioners, service providers, government, researchers and professionals from charities. Eligible participants received an email invitation to the consultation. Those who agreed to take part received a pre-workshop briefing pack and a participant consent form in advance, which they signed prior to the consultation.

\section{Design}

We used an abbreviated MORECare Transparent Expert Consultation approach consisting of a modified nominal group technique [12]. All data was collected during one half-day consultation event. At this event, we first presented to all participants $(n=27)$ place of death projections in Scotland from 2017 to 2040 based on the four scenarios described. Participants were then allocated to one of three groups consisting of care home experts $(n=10)$ primary care experts $(n=8)$ and hospice or specialist palliative care experts $(n=9)$. In each group, participants were asked to individually consider and note down what needs to be prioritised to support people to die well in each community setting by 2040 (home, care homes, hospice). A facilitator in each group guided participants through a structured process of i) brief discussion of critical issues emerging from the data; ii) individual recording of personal recommendations, and iii) sharing of individual recommendations with the wider group. A scribe wrote the recommendations on flipcharts, and group members agreed a prioritised order. Following group discussion, the top recommendations from each group were summarised by each group facilitator, typed and projected to the whole room. Finally, all participants identified individually their top three recommendations from those that emerged across all groups.

\section{Data analysis}

Individual recommendations, flipchart records of group priorities and final recommendations across all care settings were entered on Excel and categorised into themes. The top three recommendations, which at least $50 \%$ of participants prioritised during the final stage ordering, were identified. The individual and group-level priorities were examined to provide further detail relating to the top three recommendations that emerged.

\section{Ethics}

For the trend analysis, we used anonymised, aggregate and publicly available routine data, which did not require ethical approval. The Usher Research Ethics Group, University of Edinburgh approved the expert consultation (No: 1862).

\section{Results \\ Trend analysis \\ Recent mortality trends in Scotland}

Between 2004 and 2016, there was a mean of 55,260 deaths per year in Scotland. Deaths of people aged 85 or over increased from 14,634 in 2004 to 18,603 in 2016 , while the number of deaths in all other age categories declined over this period (Fig. 1).

\section{Projected mortality trends in Scotland}

There are projected to be 65,757 deaths in Scotland in 2040, a 15.9\% increase from 2016. Figure 2 shows deaths in 2016 and 2040 by age and gender, displaying a shift from younger to older ages, and a larger increase in male deaths. There are projected to be 10,960 more deaths (58.9\% increase) of people age 85 years and over in 2040 compared to 2016. Deaths of people age 85 years and over accounted for $32.8 \%$ in 2016 and will account for $45.0 \%$ by 2040 (Fig. 1).

\section{Recent trends in place of death in Scotland}

In Scotland in 2016, most people died in hospital $(n=$ $28,422,50.1 \%)$, followed by home ( $n=13,267,23.4 \%)$ and care home $(n=10,668,18.8 \%)$. A minority died in a hospice $(n=2444,4.3 \%)$. Deaths at home, in a care home and hospice increased between 2004 and 2016 while deaths in hospital decreased (Fig. 3).

\section{Projections of place of death}

Scenario 1 If age and gender specific proportions of deaths in each care setting remain unchanged from those observed in 2016, the number of deaths in hospital, home, care home, and hospice will increase (Fig. 4a and Table 1). Between 2016 and 2040, hospital deaths are projected to increase by 4565 deaths, but there will be little change in the proportion of people dying in hospital, which will remain the most common place to die (50.1\% in 2016 and 50.2\% in 2040). The annual number of home deaths is projected to increase by 588 deaths, representing a decline in the proportion of overall deaths (23.4 to $21.1 \%$ ). Annual deaths in care homes are projected to increase by 4108 deaths, and increase as a proportion of all deaths (18.8 to $22.5 \%$ ). 


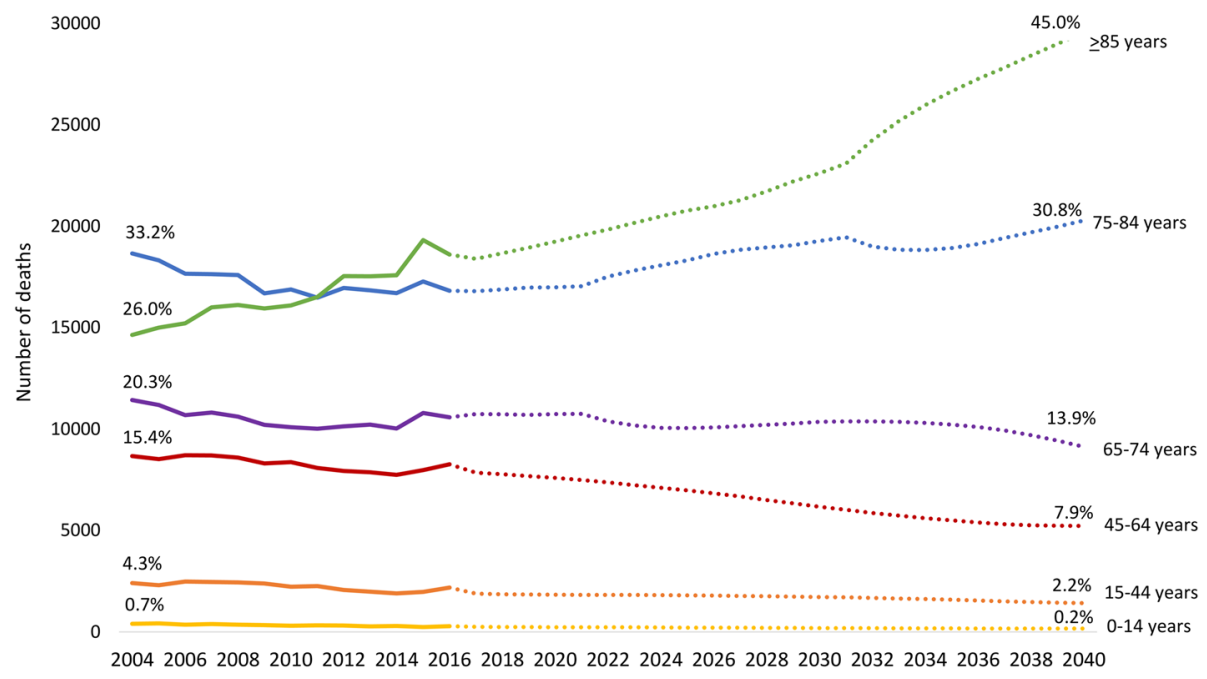

Fig. 1 Number of past deaths (2004-2016) and projected future deaths in Scotland by age group (2017-2040)

Scenario 2 If the mean yearly changes in age and gender specific proportions of deaths in each care setting observed between 2004 and 2016 continue, we project that between 2016 and 2040, the annual number of people dying in hospital will decline by 5866 deaths, representing a decline in the overall proportion of deaths (50.1 to $34.3 \%)$. The number and proportion of deaths in community settings, including home, care home and hospice, is projected to increase. Between 2016 and 2040, the annual number of home deaths is projected to increase by 6064 deaths (23.4 to $29.4 \%$ of all deaths), care home deaths by 8468 deaths (18.8 to $29.1 \%$ of all deaths) and hospice deaths by 678 deaths (4.3 to $4.7 \%$ ).

Scenario 3 If adding to scenario 2, care home deaths do not increase above the number observed in 2016, by 2040 , we project that the annual number of hospital deaths will increase by 2602 deaths, and decline as a proportion of all deaths, from 28,422 to 31,024 (50.1 to $47.2 \%)$. The proportion of care home deaths, on the other hand, would decline from 18.8 to $16.2 \%$, while the

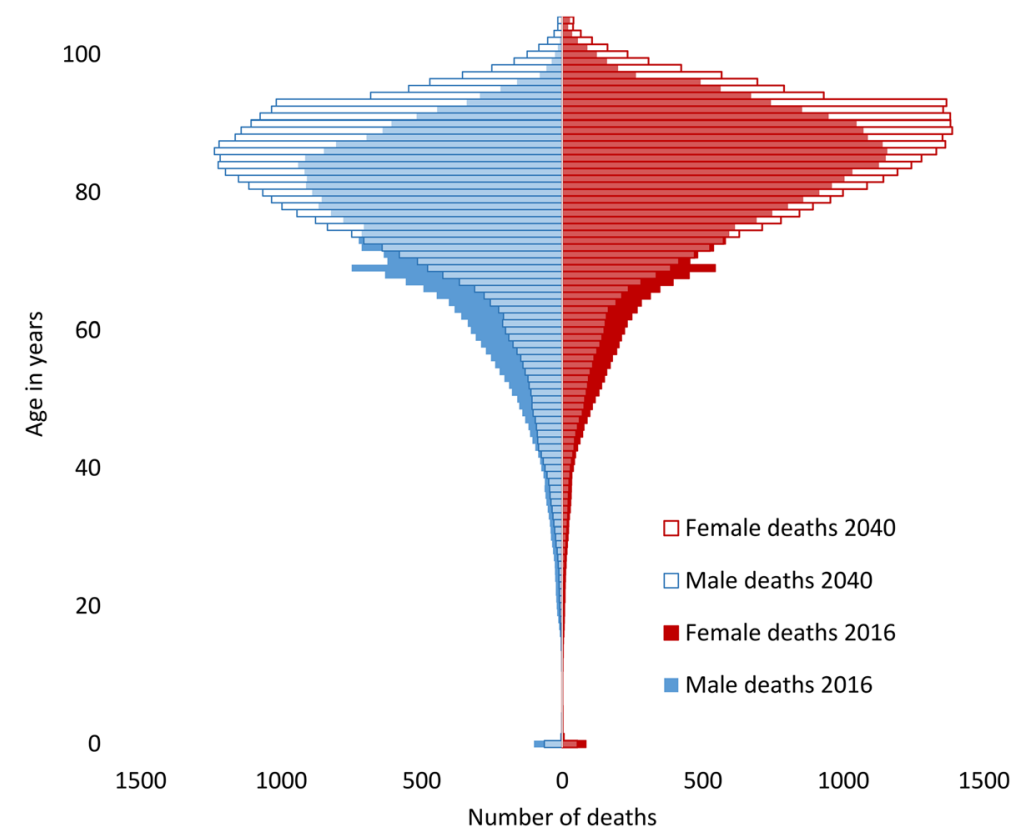

Fig. 2 Deaths in Scotland in 2016 and projected future deaths in 2040 by age and gender 


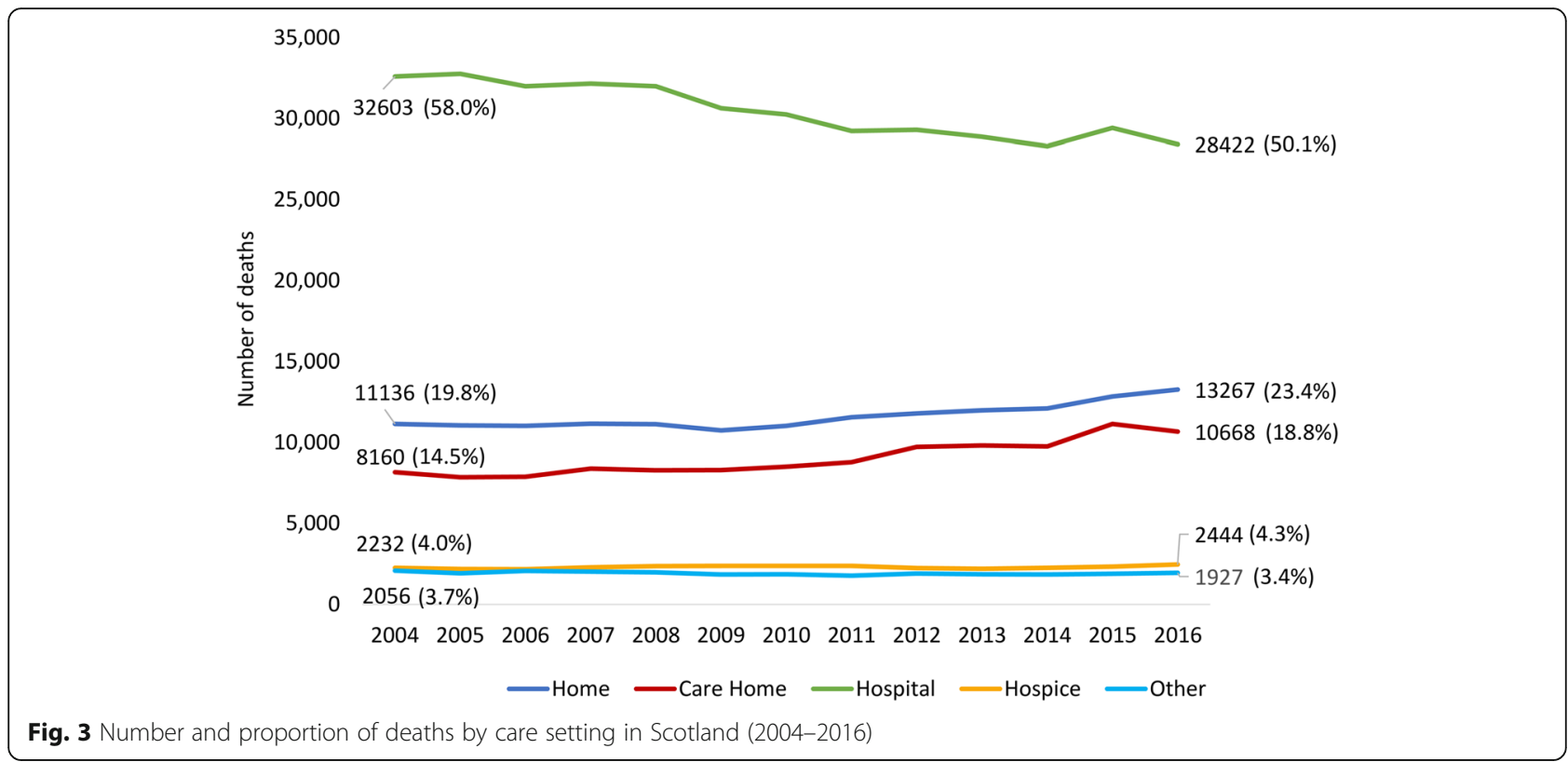

absolute number of care home deaths would remain around 10,668 .

Scenario 4 If adding to scenario 3, home deaths also do not increase above the number observed in 2016, then hospital deaths will rise from $28,422(50.1 \%)$ in 2016 to 37,089 (56.4\%) in 2040. Proportionally, care home and home deaths would gradually decrease over the years, reaching $16.2 \%$ (10,668 deaths) and $20.2 \%$ (13, 267 deaths) respectively, in 2040.

\section{Transparent expert consultation}

A transparent expert consultation was convened in October 2018 in Edinburgh. Twenty-seven experts participated comprising policy-makers, clinicians, health service managers, social care workers, educators and senior academics. The workshop generated 168 individual priorities. These were distilled down to 36 priorities during group discussions, which after further discussion and synthesis were reduced to 10 . Overlapping recommendations were amalgamated by A.M.F and A.E.B, resulting in a final set of seven priorities. Of these, consensus was greatest for three recommendations, listed below with at least half of all participants rating them as one of their top three priorities. All seven priorities with examples from individual participants are shown in Additional file 2.

Top 3 priorities:

1. Increase, equip and sustain a skilled health and social care workforce through recruitment to community posts, education, training and valuing of care work.
2. Build community capacity and resilience by providing information, practical and financial support for carers and fostering community engagement initiatives.

3. Stimulate a realistic debate on death and dying, residential care and individual choice given funding constraints.

Workforce There was consensus that workforce issues need to be urgently prioritised. Participants noted the need to increase the number of district nurses, social care staff, and GPs to meet the needs of the growing number of people expected to die by 2040. Participants agreed that the care home workforce and social carers need to be better valued for the work they do, and this should be reflected in financial reward as well as opportunities for career progression. Participants emphasized the value of training and the need to ensure all new care home staff have palliative care training during induction. They also stressed that specialist palliative care providers could build palliative care capacity in care homes through collaborative education and training initiatives.

Community capacity and resilience Participants emphasized the importance of making information, practical and financial support more widely available to informal carers of people with advanced illness and providing opportunities for education and training of carers where appropriate. They highlighted the importance of community engagement initiatives that harness the contribution of volunteers to support people to remain at home should they wish. 


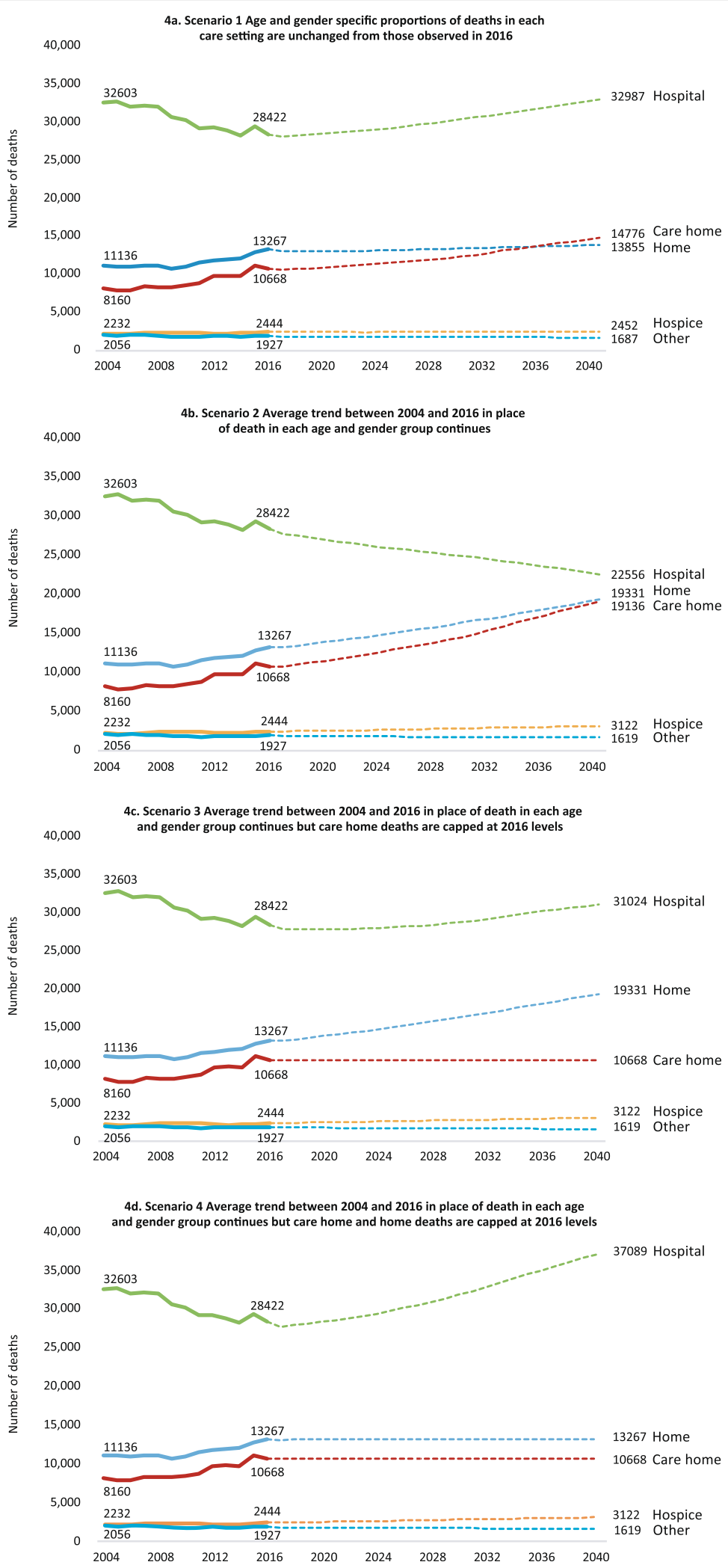

Fig. 4 Past deaths (2004-2016) and modelled scenarios for future deaths in Scotland (2017-2040) 
Table 1 Number and proportion of deaths in Scotland by place of death in 2004 and 2016 and projected estimates for 2040

\begin{tabular}{|c|c|c|c|c|c|c|c|c|c|c|c|c|}
\hline & \multicolumn{4}{|c|}{ Observed deaths } & \multicolumn{8}{|c|}{ Projected deaths in 2040} \\
\hline & \multicolumn{2}{|l|}{2004} & \multicolumn{2}{|l|}{2016} & \multicolumn{2}{|c|}{ Scenario $1^{\mathrm{a}}$} & \multicolumn{2}{|c|}{ Scenario $2^{b}$} & \multicolumn{2}{|c|}{ Scenario $3^{c}$} & \multicolumn{2}{|c|}{ Scenario $4^{d}$} \\
\hline & $\mathrm{n}$ & $\%$ & $n$ & $\%$ & $\mathrm{n}$ & $\%$ & $n$ & $\%$ & $n$ & $\%$ & $\mathrm{n}$ & $\%$ \\
\hline Home & 11136 & 19.8 & 13267 & 23.4 & 13855 & 21.1 & 19331 & 29.4 & 19331 & 29.4 & 13267 & 20.2 \\
\hline Care home & 8160 & 14.5 & 10668 & 18.8 & 14776 & 22.5 & 19136 & 29.1 & 10668 & 16.2 & 10668 & 16.2 \\
\hline Hospital & 32603 & 58.0 & 28422 & 50.1 & 32987 & 50.2 & 22556 & 34.3 & 31024 & 47.2 & 37089 & 56.4 \\
\hline Hospice & 2232 & 4.0 & 2444 & 4.3 & 2452 & 3.7 & 3122 & 4.7 & 3122 & 4.7 & 3122 & 4.7 \\
\hline Other & 2056 & 3.7 & 1927 & 3.4 & 1687 & 2.6 & 1619 & 2.5 & 1619 & 2.5 & 1619 & 2.5 \\
\hline TOTAL & 56187 & 100 & 56728 & 100 & 65757 & 100 & 65764 & 100 & 65764 & 100 & 65765 & 100 \\
\hline
\end{tabular}

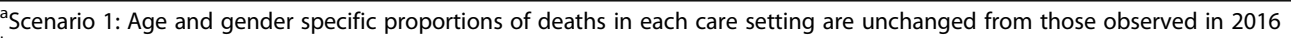

${ }^{\mathrm{b}}$ Scenario 2: Average trend between 2004 and 2016 in place of death in each age and gender group continues

'Scenario 3: Average trend between 2004 and 2016 in place of death in each age and gender group continues but care home deaths are capped at 2016 levels

${ }^{\mathrm{d}}$ Scenario 4: Average trend between 2004 and 2016 in place of death in each age and gender group continues but care home and home deaths are capped at 2016 levels

Realistic debate Participants called for a realistic and open debate on death, dying, and bereavement in society, and honest communication around what is realistic as opposed to ideal.

\section{Discussion}

Our projections show that if current Scottish trends continue (Scenario 2), the need for end-of-life care will rise over the next 20 years, particularly in home and care home settings. By 2040 community settings could feasibly account for nearly two-thirds of all deaths, and hospital could fall to approximately one-third. These findings align with those projected in England and Wales [7]. However, if community support and capacity does not radically increase, these currents trends will not be sustained. If care home capacity remains at 2016 levels, hospital deaths could increase by $9.2 \%$ by 2040 (Scenario 3). If home deaths also remain at 2016 levels, hospital deaths could increase by $30.5 \%$, representing $56.4 \%$ of all deaths by 2040 (Scenario 4). This means that most people would die in hospital, and at higher levels than was observed in 2004.

Our expert consultation findings support a continued shift toward more and better end-of-life care in the community. There is growing evidence to support the effectiveness of home based palliative care $[14,15]$. Bainbridge et al. identify the critical components of effective home based palliative care, which include linkage with hospital and community services, a multidisciplinary team and holistic approach, and access to end-of-life care training and expertise [15]. These components were also prioritised by our experts, who identified collaboration and partnership working amongst their priorities (Additional file 2). Integrated models of care, such as those providing hospital to home services, or palliative care integrated with existing services also show promise and should be considered further [16-18].
If current trends continue (Scenario 2), 29\% of people will die in care homes by 2040; this is nearly $80 \%$ more people than died in care homes in 2016 (10,668 to a projected 19,136). In Scotland, the number of care homes for older people decreased by 10\% from 949 in 2007 to 854 in 2017, and the number of care home places fell, albeit at a slower rate (from 37,540 to 37,278 ) [19]. A reversal in this trend is needed if we are to support more people to die in the community. In Switzerland and the Netherlands, over a third of people die in care homes [20] and in Norway $45.5 \%$ of people died in a care home in 2011 [21]. In the Netherlands, there are 'elderly care physicians' specialised in care for the elderly who contribute to high quality care in care home settings [22]. In Norway, the shift from hospital to care homes deaths (observed since 1987) is attributed in part to changes in cause of death (from circulatory disease to cancer to dementia) alongside policies to shift care from hospital to care homes where appropriate [21]. With supportive policies and adequate funding, shifts in place of death are therefore possible.

Experts participating in our consultation prioritised the need to increase, upskill and sustain the communitybased health and social care workforce to enable more people to die in a community setting. An increase in recruitment to primary care and community nursing is essential and is planned [23]. Critically, the social care workforce needs to increase despite significant challenges regarding recruitment to social care roles due to low pay, unsocial working hours and the emotional demands of care work [24]. Training in effective communication is essential [25] and there are approaches that could be used more widely to enhance skills [26-28], although evidence about ensuring sustained changes in practice is lacking [29]. Palliative care needs to be part of the curriculum for health and social care professionals, and students would benefit from opportunities to experience care of people with advanced progressive 
illness in primary care and care homes as part of their training [30]. This would need to be supported by appropriate tools to aid assessment and management, such as the Integrated Palliative Care Outcome Scale for Dementia (IPOS-Dem) [31, 32] and decision support [33]. Palliative care delivered in the community out-ofhours poses challenges to patient safety as most resources go into in-hours care [34]. Confidence in assessing care emergencies out-of-hours is lacking; education using flexible approaches such as e-learning are required to support GPs to deliver good emergency care at the end-of-life [35]. The social care workforce needs greater opportunities for training and development, with opportunities to progress within their role [36]. Hospices could better support community-based staff, particularly by delivering education and training in care homes and to the social care workforce. Ehealth approaches show promise and the use of video-conferencing to facilitate education and training across teams based in a variety of community settings is feasible, though further evidence of effectiveness is required [37, 38].

Experts highlighted the need to build community capacity and resilience through informal carer support and community engagement in end-of-life initiatives. Many people express a preference to die at home provided they get sufficient support and care, including home palliative care to feel safe and secure [5, 39-43]. Improving information, practical and financial support for both patients and informal carers is essential. There is a substantial network of informal carers involved in providing end-of-life care, many of whom are invisible to the health care team $[44,45]$. Routine identification of informal carers is therefore needed to ensure that carers receive adequate support in their role [46]. The Carer Support Needs Assessment Tool (CSNAT) provides a formal approach to facilitate discussions with carers about their support needs [47], with evidence to support its effectiveness [48]. Carers may also benefit from training or education regarding practical nursing tasks and administering medicines, in person or using online resources [49-51]. Public health approaches that promote community engagement provide vital support outside of professional care [52, 53]. This can involve the development of supportive communities of volunteers who provide practical and/or emotional support to people at the end-of-life and their families. Innovative models of care involving community participation need to be developed and evaluated to support a shift in end-of-life care from acute to community settings.

Experts identified the need for a realistic debate on death, dying, residential care and individual choice in context of available funding. For many people, care home is the least preferred place to die [54], yet if current trends continue it is projected that more people will die in care home settings. There is a need to stimulate open discussion on quality and funding of end-oflife care in this challenging setting, so that everyone can expect a good standard of end-of-life care and can play a role in determining where they die. This recommendation is aligned with the concept of Realistic Medicine which has emerged in Scotland $[55,56]$, and promotes realistic and honest conversations about care, including dying and bereavement, putting the person receiving health and social care at the centre of decisions made about their care.

\section{Strengths and limitations}

Our projections are not deterministic forecasts, rather scenarios based on different assumptions that can be used to inform decision-making regarding future resource allocation under certain circumstances. We assume a linear change over time, reflecting previous trends, however sudden changes in capacity (e.g. hospital closure) would result in a step-change in trends. The scenarios serve to stimulate debate, nationally and internationally, on what trends might occur under different conditions, and what trends may be best for people in Scotland.

A strength of our study is that we examine place of death for a whole country population in four key settings - hospital, home, care home and hospice. This allows comparison with other international studies and provides more nuanced data for service managers working in each and across all settings. However, these data do not shed light on patient transitions between settings and do not indicate time spent in the community versus hospital in the period before death. It also does not account for the type and quality of the care received in each setting. For example, hospice community palliative care clinical nurse specialists support many people to remain at home towards the end-of-life, yet the focus on place of death does not reflect this. Other scenarios are possible, e.g. fixed hospital capacity; and could be usefully considered alongside an economic analysis of each scenario in future studies.

Finally, a key strength is the incorporation of knowledge exchange in the study design. Engaging with a range of key stakeholders ensured that the interpretation of trend analysis findings was well-grounded in the context of health and social care provision in Scotland, with direct implications for practice and policy.

\section{Conclusion}

If current trends continue, the numbers of deaths at home and in care homes will increase and two-thirds will die outside of hospital by 2040 . However, this is very unlikely without additional investment in community-based care including care home capacity. Various actions are needed to maintain the trend: increasing and upskilling the 
community palliative care workforce; improving support for informal carers and encouraging community engagement in end-of-life care initiatives; and stimulating a realistic debate on death, dying and bereavement in context of funding constraints.

\section{Supplementary information}

Supplementary information accompanies this paper at https://doi.org/10. 1186/s12904-019-0490-x.

Additional file 1. Place of death data for Scotland: 2004-2016. Place of death sourced from the National Records of Scotland.

Additional file 2. Data from the Transparent Expert Consultation. List of the priorities identified with examples from individual participants.

\section{Abbreviations}

CSNAT: Carer Support Needs Assessment Tool; IPOS-Dem: Integrated Palliative Care Outcome Scale for Dementia; NRS: National Records of Scotland; ONS: Office of National Statistics

\section{Acknowledgements}

The authors thank the National Records of Scotland for death registration data and for separating hospice deaths from care home deaths at our request. We thank the Office of National Statistics for supplying data on future deaths for the population of Scotland by age and gender. We are grateful for Tim Warren at the Scottish Government and Katherine Ross at Scottish Care for providing helpful comments at the early stages. We also thank Sebastian Moine and Brigid Lydon for assisting with our expert consultation event in October 2018.

We presented preliminary findings from this study at the 2019 European Association of Palliative Care (EAPC) conference [57].

\section{Authors' contributions}

AMF and SAM conceived of the study concept. AEB conducted the quantitative data analysis. AMF analysed the data from the transparent expert consultation. AMF and AEB drafted the paper. AMF, AEB, SAM, BG, RM, CJE. and IJH developed the study design and participated in interpretation of data. AMF, AEB, SAM, BG, RM, CJE. and IJH critically revised the paper for important intellectual content and approved the final version to be published.

\section{Funding}

This research was funded by a research grant awarded to A.M.F and S.A.M by Marie Curie UK. The posts of A.M.F and R. M are funded by Marie Curie. A.M.F is an Honorary Fellow at the University of Edinburgh, where this study was undertaken. C.J.E is funded by a HEE/NIHR Senior Clinical Lectureship. B.G. is funded by the Calouste Gulbenkian Foundation. The views expressed in this publication are those of the author(s). The funder was not involved in the design, collection, analysis, interpretation or writing of the study.

\section{Availability of data and materials}

Place of death data analysed during the current study is available from the National Records of Scotland website: https://www.nrscotland.gov.uk/ statistics-and-data/statistics/statistics-by-theme/vital-events/deaths. We categorised place of death according to NRS reporting standards, with the exception of hospice deaths, which were separated from the 'care home' category by the NRS at our request (Additional file 1). Data on projected deaths is available on the Office for National Statistics website: https://www. ons.gov.uk/peoplepopulationandcommunity/populationandmigration/ populationprojections/compendium/nationalpopulationprojections/2016 basedprojections

\section{Ethics approval and consent to participate}

For the trend analysis, we used anonymised, aggregate and publicly available routine data, which did not require ethical approval. The Usher Research Ethics Committee, University of Edinburgh approved the expert consultation (No: 1862). Participants in the transparent expert consultation gave written informed consent to participate.
Consent for publication

Not applicable.

\section{Competing interests}

One of the authors (AMF) is a member of the Editorial Board of this journal; but had no role in the editorial process for this manuscript. R. M is Head of Policy and Public Affairs for Marie Curie Scotland. The authors declare that they have no other competing interests.

\section{Author details}

${ }^{1}$ Marie Curie Hospice Edinburgh, 45 Frogston Road West, Edinburgh, Scotland, UK. ${ }^{2}$ Usher Institute, University of Edinburgh, Edinburgh, Scotland UK. ${ }^{3}$ Cicely Saunders Institute of Palliative Care, Policy and Rehabilitation, King's College London, Bessemer Road, Denmark Hill, London SE5 9PJ, UK. ${ }^{4}$ Faculty of Medicine, University of Coimbra, Coimbra, Portugal. ${ }^{5}$ Policy and Public Affairs for Scotland, Marie Curie, Edinburgh, Scotland, UK. ${ }^{6}$ Usher Institute, University of Edinburgh, Edinburgh, Scotland, UK.

Received: 10 March 2019 Accepted: 15 November 2019

Published online: 12 December 2019

\section{References}

1. Foreman KJ, Marquez N, Dolgert A, et al. Forecasting life expectancy, years of life lost, and all-cause and cause-specific mortality for 250 causes of death: reference and alternative scenarios for 2016-40 for 195 countries and territories. Lancet. 2018. https://doi.org/10.1016/S0140-6736(18)31694-5.

2. World Population Ageing. Report no. (ST/ESA/SER.A/390), 2015. United Nations, Department of Economic and Social Affairs, Population Division. https://www.un.org/en/development/desa/population/publications/pdf/ ageing/WPA2015_Report.pdf. Accessed 25 Nov 2019.

3. National Records of Scotland. Vital Events Reference Tables 2017. Available from https://www.nrscotland.gov.uk/statistics-and-data/statistics/statisticsby-theme/vital-events/deaths. Accessed on 15 Aug 2018.

4. Office for National Statistics. National population projections: 2016-based projections, methodology, 2016. https://www.ons.gov.uk/ peoplepopulationandcommunity/populationandmigration/ populationprojections/compendium/nationalpopulationprojections/2016 basedprojections. Accessed 13 Aug 2018.

5. Gomes B, Calanzani N, Gysels M, et al. Heterogeneity and changes in preferences for dying at home. Bmc Palliat Care. 2013;12:7. https://doi.org/ 10.1186/1472-684X-12-7 Article.

6. Connor S, Sepulveda C. Global atlas of palliative Care at the end of life. London UK and Geneva Switzerland: Worldwide Hospice Palliative Care Alliance and World Health Organization; 2014.

7. Bone $A E$, Gomes $B$, Etkind $S N$, et al. What is the impact of population ageing on the future provision of end-of-life care? Population-based projections of place of death. Palliat Med. 2018;32:329-36. https://doi.org/10. $1177 / 0269216317734435$

8. Sarmento VP, Higginson IJ, Ferreira PL, et al. Past trends and projections of hospital deaths to inform the integration of palliative care in one of the most ageing countries in the world. Palliat Med. 2016;30:363-73. https://doi.org/10.1177/0269216315594974.

9. Simon ST, Gomes B, Koeskeroglu P, et al. Population, mortality and place of death in Germany (1950-2050) - implications for end-of-life care in the future. Public Health. 2012;126:937-46. https://doi.org/10.1016/j.puhe.2012.06.014.

10. Houttekier D, Cohen J, Surkyn J, et al. Study of recent and future trends in place of death in Belgium using death certificate data : a shift from hospitals to care homes. BMC Public Health. 2011;11. https://doi.org/10. 1186/1471-2458-11-228.

11. Gomes B, Higginson IJ. Where people die (1974-2030): past trends, future projections and implications for care. Palliat Med. 2008;22:33-41. https://doi.org/10.1177/0269216307084606.

12. Higginson IJ, Evans CJ, Grande G, et al. Evaluating complex interventions in End of Life Care: the MORECare Statement on good practice generated by a synthesis of transparent expert consultations and systematic reviews. BMC Med. 2013;11:111. https://doi.org/10.1186/1741-7015-11-111 journal article.

13. Gomes B, Calanzani N, Higginson IJ. Reversal of the British trends in place of death: time series analysis 2004-2010. Palliat Med. 2012;26:102-7. https://doi.org/10.1177/0269216311432329.

14. Gomes B, Calanzani N, Curiale V et al. Effectiveness and cost-effectiveness of home palliative care services for adults with advanced illness and their 
caregivers. Cochrane Database Syst Rev. 2013:CD007760. https://doi.org/10 1002/14651858.CD007760.pub2.

15. Bainbridge $D$, Seow H, Sussman J. Common components of efficacious inhome end-of-life Care programs: a review of systematic reviews. J Am Geriatr Soc. 2016;64:632-9. https://doi.org/10.1111/jgs.14025.

16. Brighton $L$, Miller S, Farquhar M, et al. Holistic services for people with advanced disease and chronic breathlessness: a systematic review and meta-analysis. Thorax. 2019;74:270-81. https://doi.org/10.1136/thoraxjnl2018-211589.

17. Bajwah S, Ross JR, Wells AU, et al. Palliative care for patients with advanced fibrotic lung disease: a randomised controlled phase II and feasibility trial of a community case conference intervention. Thorax. 2015;70:830-9. https://doi.org/10.1136/thoraxjnl-2014-206583.

18. Higginson IJ, Bausewein C, Reilly CC, et al. An integrated palliative and respiratory care service for patients with advanced disease and refractory breathlessness: a randomised controlled trial. Lancet Respir Med. 2014;2: 979-87. https://doi.org/10.1016/S2213-2600(14)70226-7.

19. Information Services Division Scotland. Care home census for adults in Scotland: figures for 2007-2017. 2018.

20. Broad J, Gott M, Kim H, et al. Where do people die? An international comparison of the percentage of deaths occurring in hospital and residential aged care settings in 45 populations, using published and available statistics. Int J Public Health. 2013;58:257-67. https://doi.org/10. 1007/s00038-012-0394-5.

21. Kalseth J, Theisen OM. Trends in place of death: the role of demographic and epidemiological shifts in end-of-life care policy. Palliat Med. 2017;31: 964-74. https://doi.org/10.1177/0269216317691259.

22. Verenso. Elderly care physicians in the Netherlands, professional profile and competencies. English translation of original Dutch publication (Beroepsprofiel en competenties specialist ouderengeneeskunde, 2012). The Netherlands: Dutch Association of Elderly Care Physicians and Social Geriatricians; 2015

23. Scottish Government. National Health and social Care workforce plan: part 3 - improving workforce planning for primary care in Scotland. 2018.

24. Scottish Care. The 4 Rs: the open doors of recruitment and retention in social Care. 2018.

25. Ventura AD, Burney S, Brooker J, et al. Home-based palliative care: a systematic literature review of the self-reported unmet needs of patients and carers. Palliat Med. 2014;28:391. https://doi.org/10.1177/ 0269216313511141.

26. Clayton JM, Butow PN, Waters A, et al. Evaluation of a novel individualised communication-skills training intervention to improve doctors' confidence and skills in end-of-life communication. Palliat Med. 2013;27:236 https://doi.org/10.1177/0269216312449683.

27. Griffiths J, Wilson C, Ewing G, et al. Improving communication with palliative care cancer patients at home - A pilot study of SAGE \& THYME communication skills model. Eur J Oncol Nurs. 2015;19:465-72. https://doi. org/10.1016/j.ejon.2015.02.005.

28. Grainger MN, Hegarty S, Schofield P, et al. Discussing the transition to palliative care: evaluation of a brief communication skills training program for oncology clinicians. Pall Support Care. 2010;8:441-7. https://doi.org/10. 1017/S1478951510000313.

29. Selman LE, Brighton $\sqcup$, Hawkins A, et al. The Effect of Communication Skills Training for Generalist Palliative Care Providers on Patient-Reported Outcomes and Clinician Behaviors: A Systematic Review and Metaanalysis. J Pain Symptom Manag. 2017;54:404-416.e405. https://doi.org/ 10.1016/j.jpainsymman.2017.04.007

30. Bowden J, Dempsey K, Boyd K, et al. Are newly qualified doctors prepared to provide supportive and end-of-life care? A survey of foundation year 1 doctors and consultants. J R Coll Physicians Edinb. 2013;43:24. https://doi. org/10.4997/JRCPE.2013.105.

31. Ellis-Smith C, Evans CJ, Murtagh FE, et al. Development of a caregiverreported measure to support systematic assessment of people with dementia in long-term care: the integrated palliative care outcome scale for dementia. Palliat Med. 2017;31:651-60. https://doi.org/10.1177/ 0269216316675096.

32. Ellis-Smith C, Rosenthal M, Higginson IJ, et al. How can a measure improve assessment and management of symptoms and concerns for people with dementia in care homes? A mixed-methods feasibility and process evaluation of IPOS-Dem. PLoS One. 2018;13:E0200240. https://doi.org/10. 1371/journal.pone.0200240.
33. van Vliet LM, Harding R, Bausewein C, et al. How should we manage information needs, family anxiety, depression, and breathlessness for those affected by advanced disease: development of a clinical decision support tool using a Delphi design. BMC Med. 2015;13. https://doi.org/10.1186/ s12916-015-0449-6.

34. Williams $H$, Donaldson SL, Noble S, et al. Quality improvement priorities for safer out-of-hours palliative care: Lessons from a mixed-methods analysis of a national incident-reporting database. Palliat Med. 2018:0269216318817692. https://doi.org/10.1177/0269216318817692.

35. Magee C, Koffman J. Out-of-hours palliative care: what are the educational needs and preferences of general practitioners? BMJ Support Palliat Care. 2016;6:362-8. https://doi.org/10.1136/bmjspcare-2014-000764.

36. Scottish Care. Trees that bend in the wind: Exploring the Experiences of Front Line Support Workers Delivering Palliative and End of Life Care, 2017. http://www.scottishcare.org/wp-content/uploads/2017/02/PEOLC-Reportfinal-pdf.

37. White C, Mcllfatrick S, Dunwoody L, et al. Supporting and improving community health services-a prospective evaluation of ECHO technology in community palliative care nursing teams. BMJ Support Palliat Care. 2015. https://doi.org/10.1136/bmjspcare-2015-000935.

38. Capurro D, Ganzinger M, Perez-Lu J, et al. Effectiveness of eHealth interventions and information needs in palliative care: a systematic literature review. J Med Internet Res. 2014;16:e72. https://doi.org/10. 2196/jmir.2812.

39. Fukui S, Yoshiuchi K, Fujita J, et al. Japanese People's preference for place of end-of-life Care and death: a population-based Nationwide survey. J Pain Symptom Manag. 2011;42:882-92. https://doi.org/10.1016/j.jpainsymman. 2011.02.024.

40. Gu X, Cheng W, Cheng M, et al. The preference of place of death and its predictors among terminally ill patients with Cancer and their caregivers in China. Am J Hosp Palliat Med. 2014;32:835-40. https://doi.org/10.1177/ 1049909114542647.

41. Gomes B, Calanzani N, Gysels M, et al. Heterogeneity and changes in preferences for dying at home:a systematic review. BMC Palliat Care. 2013. https://doi.org/10.1186/1472-684X-12-7.

42. Gott M, Seymour J, Bellamy G, et al. Older people's views about home as a place of care at the end of life. Palliat Med. 2004;18:460-7. https://doi.org/ 10.1191/0269216304pm889oa.

43. Sarmento VP, Gysels M, Higginson IJ, et al. Home palliative care works: but how? A meta-ethnography of the experiences of patients and family caregivers. BMJ Support Palliat Care. 2017;7:00. https://doi.org/10.1136/ bmjspcare-2016-001141.

44. Carduff E, Finucane A, Kendall M, et al. Understanding the barriers to identifying carers of people with advanced illness in primary care. BMC Fam Pract. 2014;15:48. https://doi.org/10.1186/1471-2296-15-48.

45. Burns CM, Abernethy AP, Dal Grande E, et al. Uncovering an invisible network of direct caregivers at the end of life: a population study. Palliat Med. 2013;27:608. https://doi.org/10.1177/0269216313483664

46. Carduff $E$, Jarvis A, Highet $G$, et al. Piloting a new approach in primary care to identify, assess and support carers of people with terminal illnesses. BMC Fam Pract. 2016;17:18. https://doi.org/10.1186/s12875-0160414-2.

47. Ewing G, Brundle C, Payne S, et al. The Carer Support Needs Assessment Tool (CSNAT) for Use in Palliative and End-of-life Care at Home: A Validation Study. J Pain Symptom Manag. 2013;46:395-405. https://doi.org/10.1016/j. jpainsymman.2012.09.008.

48. Aoun S, Deas K, Toye $C$, et al. Supporting family caregivers to identify their own needs in end-of-life care: qualitative findings from a stepped wedge cluster trial. Palliat Med. 2015;29:508-17. https://doi.org/10.1177/ 0269216314566061

49. Bee PE, Barnes P, Luker KA. A systematic review of informal caregivers' needs in providing home-based end-of-life care to people with cancer. J Clin Nursing. 2009;18(10):1379-93.

50. Flemming K, Atkin K, Ward C, et al. Adult family carer's perceptions of their educational needs when providing end-of-life care: a systematic review of qualitative research [version 1; referees: awaiting peer review]. AMRC Open Res. 2019;1. https://doi.org/10.12688/amrcopenres.12855.1.

51. Forbat $L$, Robinson $R$, Bilton-Simek $R$, et al. Distance education methods are useful for delivering education to palliative caregivers: a single-arm trial of an education package (PalliativE caregivers education package). Palliat Med. 2017;32:581-8. https://doi.org/10.1177/0269216317712849. 
52. Abel J, Kellehear A. Palliative care reimagined: a needed shift. BMJ Supportive \&amp. Palliat Care. 2016;6:21-6. https://doi.org/10.1136/ bmjspcare-2015-001009.

53. Sallnow $L$, Paul $S$. Understanding community engagement in end-oflife care: developing conceptual clarity. Crit Public Health. 2014:1-8. https://doi.org/10.1080/09581596.2014.909582.

54. Calanzani N, Moens K, Cohen J, et al. Choosing care homes as the least preferred place to die: a cross-national survey of public preferences in seven European countries. 2014. https://doi.org/10.1186/1472-684X-13-48.

55. Scottish Government. Realistic Medicine: Chief Medical Officer's Annual Report 2014-15. 2016. Available at www.gov.scot.

56. Scottish Government. Realising Realistic Medicine: Chief Medical Officer's Annual Report 2015-16. 2017. Available at www.gov.scot.

57. Finucane A, Bone $A E$, Evans $C J$, et al. European Association for Palliative Care (EAPC) Abstracts: The impact of population aging on end-of-life care in Scotland: Population-based projections of place of death and recommendations for future service provision. Palliat Med. 2019;33:118-589. https://doi.org/10.1177/0269216319844405 Abstract No. P101-332.

\section{Publisher's Note}

Springer Nature remains neutral with regard to jurisdictional claims in published maps and institutional affiliations.

Ready to submit your research? Choose BMC and benefit from:

- fast, convenient online submission

- thorough peer review by experienced researchers in your field

- rapid publication on acceptance

- support for research data, including large and complex data types

- gold Open Access which fosters wider collaboration and increased citations

- maximum visibility for your research: over $100 \mathrm{M}$ website views per year

At BMC, research is always in progress.

Learn more biomedcentral.com/submissions 